\title{
New record of Phyllodiaptomus (Ctenodiaptomus) praedictus sulawensis Alekseev \& Vaillant, 2013 (Hexanauplia, Copepoda, Calanoida, Diaptomidae) in the Philippines (Luzon Island)
}

\author{
Shea Kathleen P. Guinto ${ }^{1}$, Justine Val Jade B. Lacaba ${ }^{2}$, John Kenneth V. Cuballes ${ }^{2}$, Aezrile A. Igancio ${ }^{2}$, Eric Zeus C. Rizo ${ }^{3}$, \\ Henri J. Dumont ${ }^{3,4}$, Bo-Ping Han ${ }^{3} \&$ Rey Donne S. Papa ${ }^{1,2,5 *}$
}

\begin{abstract}
A study originally intended to update the taxonomy and distribution of calanoid copepods in selected freshwater ecosystems of Central Luzon has led to the discovery of a new record of Phyllodiaptomus Kiefer, 1936 in Candaba Swamp, Pampanga. Since 1979, the only calanoid copepods recorded from this area included Filipinodiaptomus insulanus (Wright S., 1928) and Tropodiaptomus australis Kiefer, 1936. Later studies on calanoid copepods in the region have since been non-existent. Analyses of pertinent key morphological characters revealed that the specimens at hand belonged to Phyllodiaptomus (Ctenodiaptomus) praedictus sulawensis Alekseev \& Vaillant, 2013, a freshwater diaptomid calanoid copepod subspecies discovered and known to be endemic only in Indonesia. Provided in this paper are baseline information on the morphological characters of the Philippine members of the subspecies accompanied by line drawings as well as a comparison between the recorded morphological data presented by Alekseev, Haffner, Vaillant \& Yusoff (2013) and the current dataset to support the identification of the specimen. The discovery of $P$. (C.) praedictus sulawensis in the Philippines, which was thought to be endemic in Indonesia, presents a new record of this species in the country and the first such record outside of its country of origin.
\end{abstract}

KEYWORDS: Candaba Swamp, Copepod, Indonesia, Inland Waters, Limnology, Thailand

\section{INTRODUCTION}

The genus Phyllodiaptomus Kiefer, 1936 is comprised of two subgenera proposed by Dumont et al. (1996), namely Phyllodiaptomus (Ctenodiaptomus) having a total of 6 species and Phyllodiaptomus (Phyllodiaptomus) comprised of 5 species. Moreover, Phyllodiaptomus has been known to be a freshwater genus often found in ponds, irrigation canals, and other inland waters usually exposed to anthropogenic activities. In fact, one species, $P$. wellekensae Dumont \& Reddy, 1993 is considered a vulnerable species being endemic to a man-made pond found in Kanyakumari, Tamilnandu, South India (Reid, 1996). To date, members of the genus have been recorded within central, southern, south-

${ }^{1}$ The Graduate School, University of Santo Tomas, Manila, Philippines ${ }^{2}$ Department of Biological Sciences, University of Santo Tomas, Manila, Philippines

${ }^{3}$ Institute of Hydrobiology, Jinan University, Guangzhou, China

${ }^{4}$ Department of Biology, University of Ghent, Belgium

${ }^{5}$ Research Center for Natural and Applied Sciences, University of Santo Tomas, Manila, Philippines

Corresponding Author: rspapa@ust.edu.ph

Date Submitted: 07 May 2018

Date Accepted: 09 September 2018 eastern, and eastern Asia with majority found in Thailand and India. More specifically, Phyllodiaptomus (Ctenodiaptomus) praedictus Dumont \& Ranga Reddy, 1994 was originally described from Bangkok, Thailand, and was initially reported as Phyllodiaptomus annae (Apstein, 1907) by Lai \& Fernando (1980). Further studies by Dumont \& Reddy (1994) then found out that the $P$. annae previously studied by Lai \& Fernando (1980) was misidentified and was then transferred to $P$. (C.) praedictus and considered it as the seventh species under the genus Phyllodiaptomus (Dumont \& Reddy, 1994). Furthermore, Alekseev et al. (2013) have discovered P. (C.) praedictus in Lake Tondano in Sulawesi Island, Indonesia, the first record of the species in insular Southeast Asia. This has resulted to a new subspecies $P$. (C.) praedictus sulawensis Alekseev \& Vaillant, 2013 based on specific morphological characters different from the $P$. (C.) praedictus population in mainland Asia. During this time, they believed that $P$. (C.) praedictus sulawensis was endemic in Lake Tondano and its nearby inland waters (Alekseev et al., 2013).

To date, there are a total of 12 inland water calanoid copepod species recorded in the Philippines which belong 
to five genera (Arctodiaptomus, Filipinodiaptomus, Mongolodiaptomus, Tropodiaptomus and Pseudodiaptomus) with five species still needing confirmation by conducting further sampling in their previously known collection sites (Lopez et al., 2017). In 2013, R. Papa, H. Dumont, \& E. Rizo (unpublished) were able to identify Phyllodiaptomus specimens from Candaba Swamp, Central Luzon although they were not able to proceed with the identification up to species level. In order to resolve this, more specimens from the said locality were collected and identified to be $P$. (C.) praedictus sulawensis using line drawings. $P$. (C.) praedictus sulawensis is one of only two calanoid copepod species recorded from the area, the other being the invasive Arctodiaptomus dorsalis (Marsh, 1932), which has been observed to have been introduced through non-native fishes, particularly those used in the aquarium and aquaculture trades (Papa et al., 2012). With the presence of $A$. dorsalis in a large number of inland waters in the Philippines, there is much greater need not only for copepod biodiversity and distribution studies but also for intensive taxonomic work due to the lack of baseline information on copepod taxonomy in the country. Thus, we now provide information on the current occurrence of $P$. (C.) praedictus sulawensis in Candaba Swamp, Pampanga and provide taxonomic information needed for species identification of the Philippine members of the subspecies.

\section{MATERIALS AND METHODOLOGY}

Sampling was conducted last November 2016 in Candaba

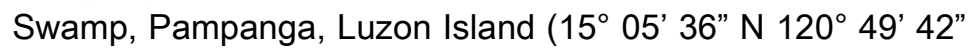
E) (Fig. 1). A major wetland found in Central Luzon covered by three provinces (Bulacan to its east-southeast, Nueva Ecija to its north, and Pampanga to its west-southwest), Candaba Swamp is one of the Key Biodiversity Areas (KBA) and Important Bird and Biodiversity Areas (IBA) in the Philippines. This area serves as a catch basin for the Maasim, San Miguel, Garlang, Bulu, and Penaranda rivers, especially during the monsoon season. The swamp then drains to Manila Bay through the Pampanga River (Ong et al., 2005). From January to May, the swamp serves as rice field and fruit plantations, but from June to December, the area is used for fisheries and serves as a wintering ground for migratory birds.

A total of 87 samples from 77 sites were collected using conical plankton nets with mesh sizes $90 \mu \mathrm{m}$ and $50 \mu \mathrm{m}$ via horizontal tow for irrigation canals as well as rice fields and temporary fish ponds with a maximum of depth of $1.27 \mathrm{~m}$. At least $1 \mathrm{~L}$ of water samples were also collected from the periphery of some rice fields and then filtered through a 90 $\mu \mathrm{m}$ mesh. All samples were fixed with $95 \%$ ethyl alcohol, sieved using $70 \mu \mathrm{m}$ and $45 \mu \mathrm{m}$ sieves, and fixed in $70 \%$ ethyl alcohol with Rose Bengal dye. Calanoid copepods were

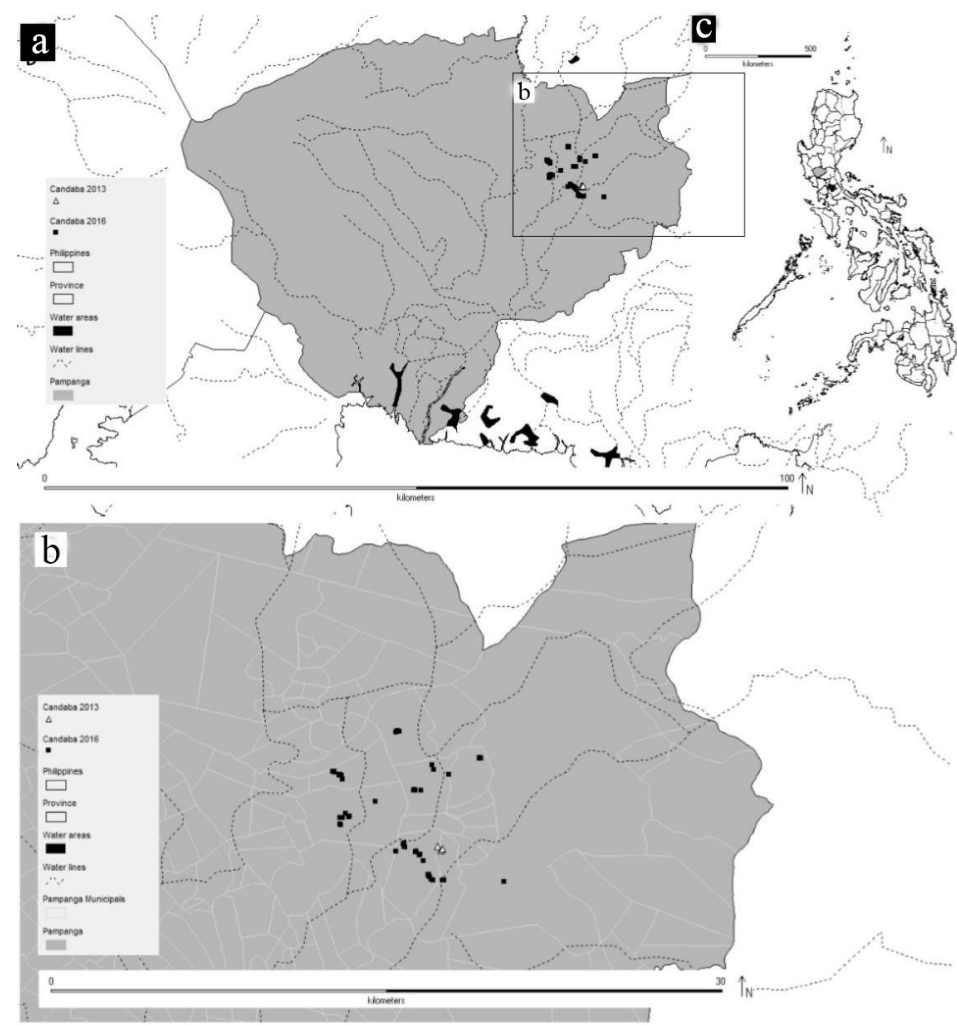

Figure 1. (A) Pampanga, Philippines., (B) Location of Candaba within the province of Pampanga; Close-up view showing the sites where $P$. (C.) praedictus sulawensis was recorded within the sampling area. Triangle plots indicate samples from 2013 and square plots indicate samples from 2016, (C) Overview map showing the location of Pampanga Province in Central Luzon, Philippines.

sorted and tentatively identified to the lowest possible taxonomic classification. Dissection was done using fine tungsten needles under a BestScope Stereomicroscope. Specimens were mounted in slides using glycerine as a mounting medium and sealed with a cover slip using clear nail polish as sealant. Body length measurements, further taxonomic observations, and the line drawings were made using an Olympus CX21 compound microscope with an attached drawing tube. Dissected specimens were also subjected to phase contrast microscopy using an Optika B500 Phase Contrast Microscope and the Optika Software. Phase contrast micrographs were then aligned to produce digitized line drawings using Adobe Photoshop CC.

\section{Materials Examined}

Previously collected samples deposited at the University of Santo Tomas - Zooplankton Reference Collection (USTZRC Sample Ref. Nos. 0116-0121 and 1579-1665) which were collected in Candaba swamp in January 2013, and 87 samples collected from the same area in November 2016 from a total of 19 sites were used in the study. Identification was aided by descriptions, taxonomic keys and illustrations by Dumont \& Reddy (1993), Dumont et al. (1996), Dumont \& 
Reddy (1994), Dussart \& Defaye (2001) Lai et al. (1979), and Sanoamuang \& Yindee (2001), and Alekseev et al. (2013). There were a total of 40 mounted specimens used in the line drawings and description of the species which were deposited at the University of Santo Tomas - Zooplankton Reference Collection (UST-ZRC Slide Ref. Nos. 238-252 and 262-286).

\section{TAXONOMIC TREATMENT}

Order Calanoida G.O. Sars, 1903

Family Diaptomidae Baird, 1850

Genus Phyllodiaptomus Kiefer, 1936

Subgenus Phyllodiaptomus (Ctenodiaptomus) Dumont,

Ranga Reddy \& Sanoamuang, 1996

Species Phyllodiaptomus (Ctenodiaptomus) praedictus

Dumont \& Ranga Reddy, 1994

Subspecies Phyllodiaptomus (Ctenodiaptomus) praedictus sulawensis Alekseev \& Vaillant, 2013

\section{Adult Female}

Habitus (Fig. 2-A) Mean total length exclusive of furcal setae $1.33 \mathrm{~mm} \pm 0.04 \mathrm{~mm}(\mathrm{n}=30)$. Rostral spines (Fig. 2-B) moderately developed and acute. Fourth and fifth pedigerous somite separated by distinct septum. Fifth pedigerous somite lateral wings asymmetrical, with outer and inner spines; left wing triangular, posterolaterally directed, not overlapping the margin of genital somite; right wing bilobed.

Antennules (Figs. 2-K, L, \& M) 25-segmented, extending beyond furcal setae; armature (segment $=$ setae + aesthetasc) as normally found in genus: $1,3-7,9,11,15-19$, $21-24=1 ; 13=a e ; 14=1+$ ae; $20=1$ spine; $8,12=1+1$ spine; $25=4$ ).

Urosome (Fig. 2-G) three-segmented; genital somite greater in length than the other 2 succeeding somites including furcal setae; right margin of genital somite distinctly enlarged, preceded by an indentation; left side enlarged at the proximal portion; both sides with one genital spine positioned on opposite sides located dorsolaterally directed posterolaterally; Genital pore (Fig. 3-E) with prominent fold on each side having a genital septum which divides the genital plates covering into two external gonopores. Second urosomite smallest, proximal portion partially inserted in genital somite. Anal somite equal in length as inner margins of furcel setae with setules; Furcal setae adorned with setules except for the dorsal seta of the furca, innermost furcal seta of each furca with slight bulge at the base on outer side.

Fifth pediger (P5; Fig. 2-I) symmetrical, coxa wide and somewhat rectangular, with a conical blunt spine located posterolaterally at the distal margin. Basis triangular in shape, smaller than the coxa, with long sensory setae almost reaching up to the base of third exopod segment. Exopod 3segmented; first exopod segment, cylindrically-shaped, longer than wide; second exopod segment shaped as a terminal claw; with lateral spine almost equal in length but thinner than outer spine on third exopod segment. Third exopod segment triangular and smallest; with two unequal setae: a shorter outer spine as long as lateral spine of second exopod segment, and a longer inner serrated spine extending almost at the end of the previous segment. Terminal claw (Fig. 2-J) inner margin with 21 spinules and outer margin with 5 spinules, third exopod segment tip with pore. Endopod 2-segmented, sturdy, about as long as the inner margin of the first exopod segment; tip of second exopod segment rounded, with transverse row of closely arranged spinules, and with slightly larger spine on each side.

Antennae (Fig. 3-A) biramous, with basipod bearing two distal setae and no proximal setae. Exopod, 2-segmented, first segment as long as the basipod bearing two setae; second segment smaller than first bearing seven terminal setae and six-subterminal setae, and one smaller lateral setae. Endopod, apparently eight-segmented, segments of different sizes, segments 1-3 and segments 4-7 nearly of equal length bearing one seta each. Segment eight as long as all other segments combined with three terminal setae.

Mandible (Fig. 3-B) with gnathal lobe heavily chitinized, bearing eight fine teeth and a large one, in addition to a finely plumose seta. Basipod of palp with four inner marginal setae, one simple middle, two plumose distal and one simple distal. Exopod 2- segmented, first segment bearing one small simple distal terminal seta and one small simple distal marginal seta, second segment with seven terminal setae and seven spinules on the mid-dorsal side. Endopod small, four-segmented; proximal segment largest, remaining segments of approximately equal size. First segment to third segment with one distal marginal seta each; distal segment bearing three terminal setae.

Maxilla (Fig. 3-C) with five large medial lobes (endite) and three smaller terminal lobes; antepenultimate lobe with three setae, penultimate lobe bearing two setae, terminal lobe the smallest, with one seta; marginal lobes bearing $4,3,3,3$, and 4 setae, respectively, as well as one separate proximal seta near base of first endite.

Maxillule (Fig. 3-D) with gnathobase or first inner lobe bearing ten thick outer spines and four smaller spines at the posterior, second inner lobe and third inner lobe with four inner terminal setae each. Coxal epipod or outer lobe with nine long setae. Exopod bearing six marginal setae, and one small marginal seta found protruding between outer lobe and 


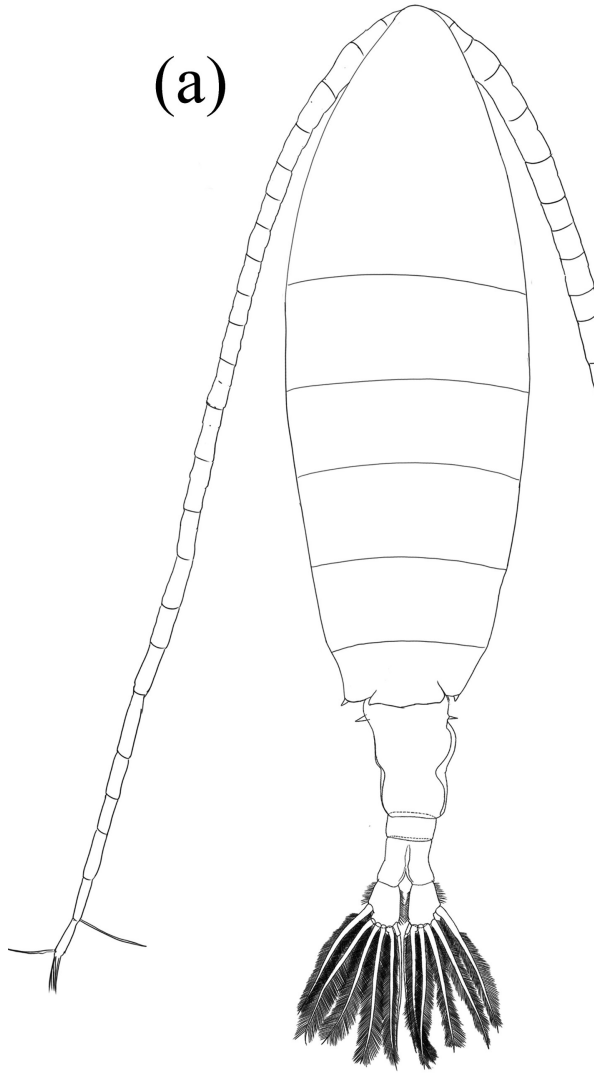

(i)

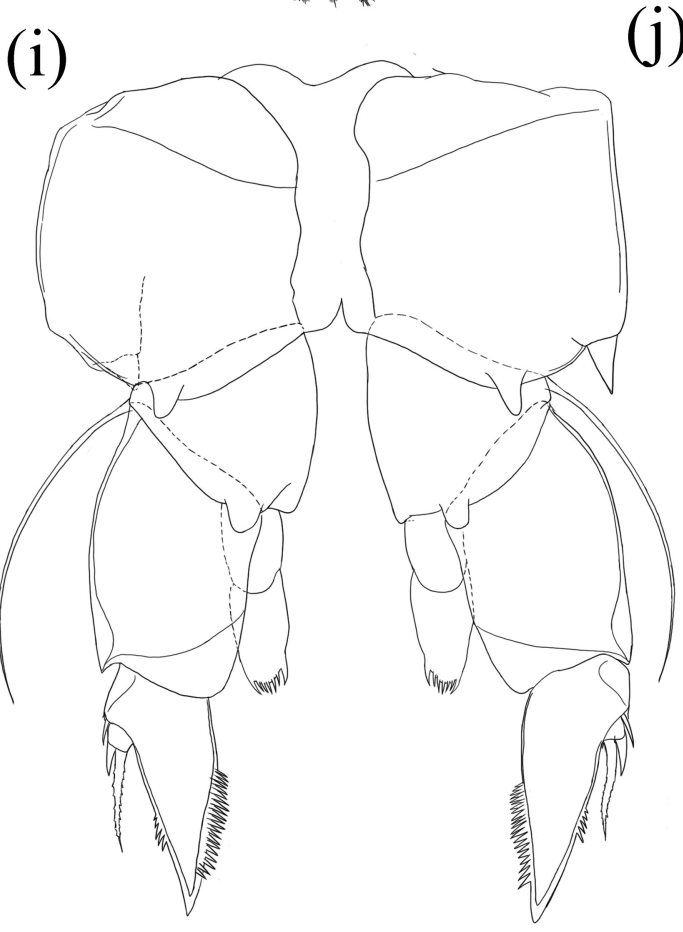

(b) (e)

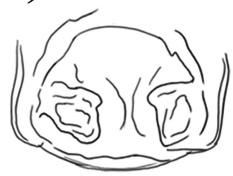

(c)

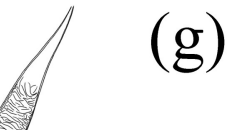

(f)

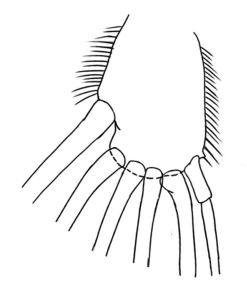

(d)

(k)

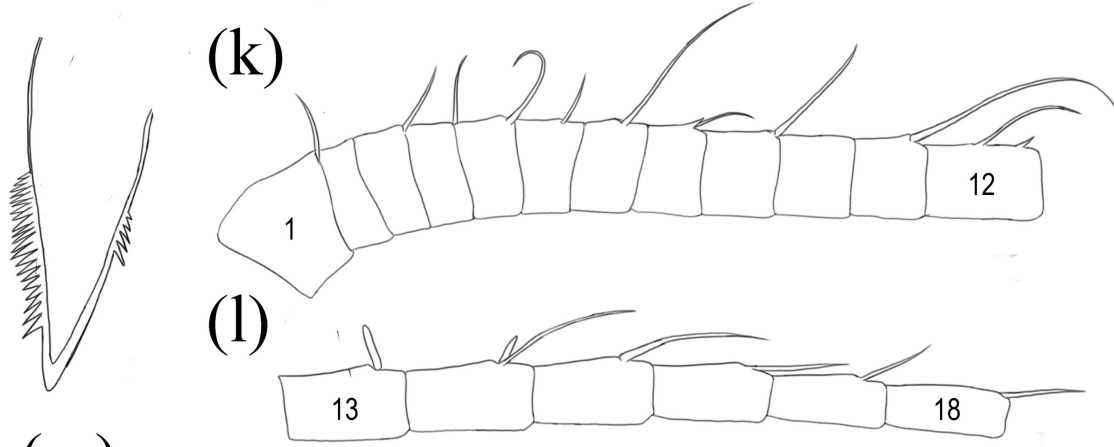

(m)
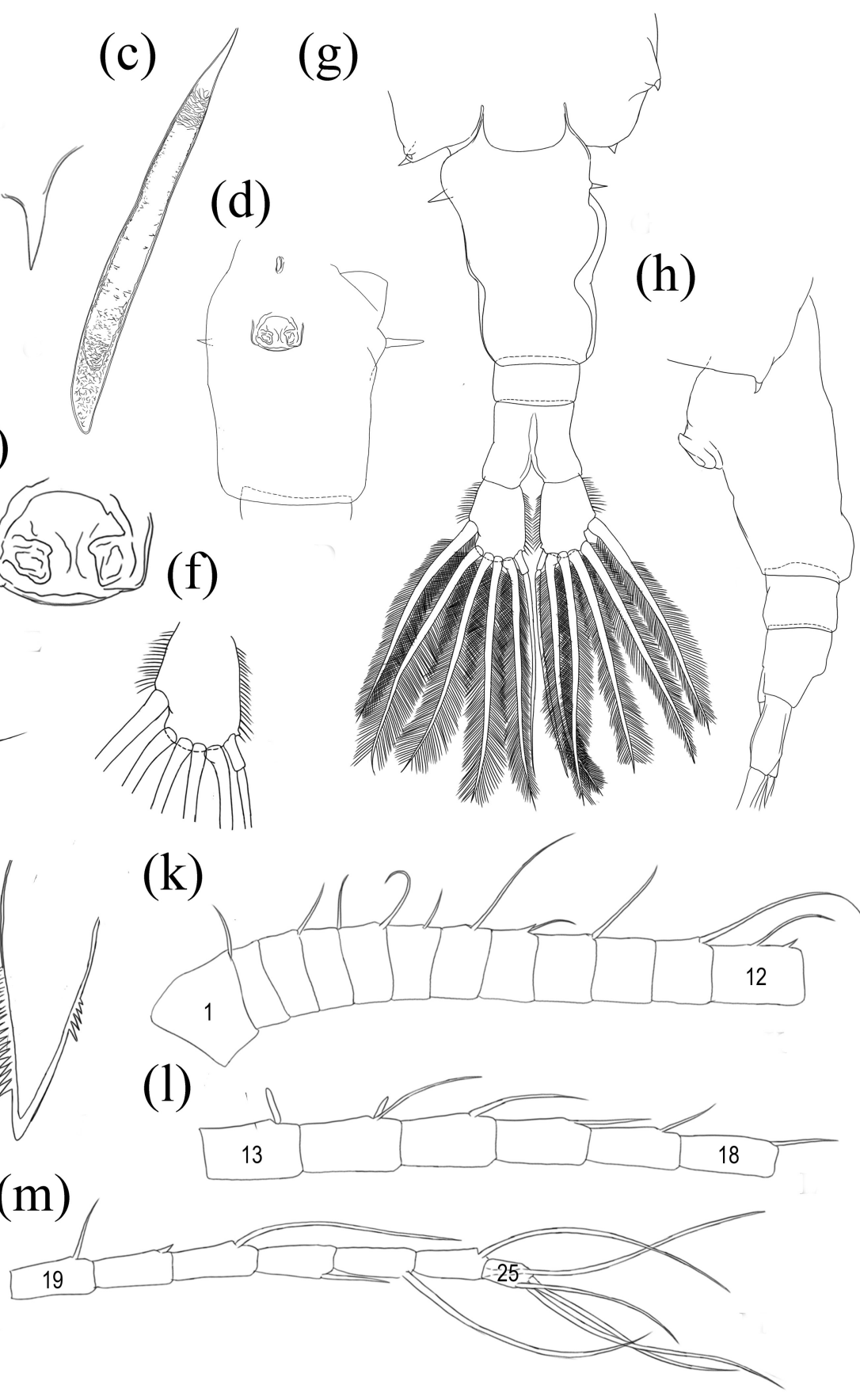

$500 \mu \mathrm{m}$

(a)

$(e, j) \stackrel{25 \mu m}{\longmapsto}(f)$

$(\mathrm{b}, \mathrm{i}) \stackrel{75 \mu \mathrm{m}}{\longrightarrow}(\mathrm{c}-\mathrm{d}, \mathrm{g}-\mathrm{h}, \mathrm{k}-\mathrm{m})$

Figure 2. Female Phyllodiaptomus (Ctenodiaptomus) praedictus sulawensis. A, habitus; B, frontal view of rostrum; C, spermatophore; D, genital somite in ventral view; E, genital field; F, left caudal ramus dorsal view; G, fifth pedigerous somite and urosome; $\mathrm{H}$, left side of the fifth pedigerous somite and urosome; I, P5 posterior view; J, terminal claw of the fifth leg; K-M, antennule. 


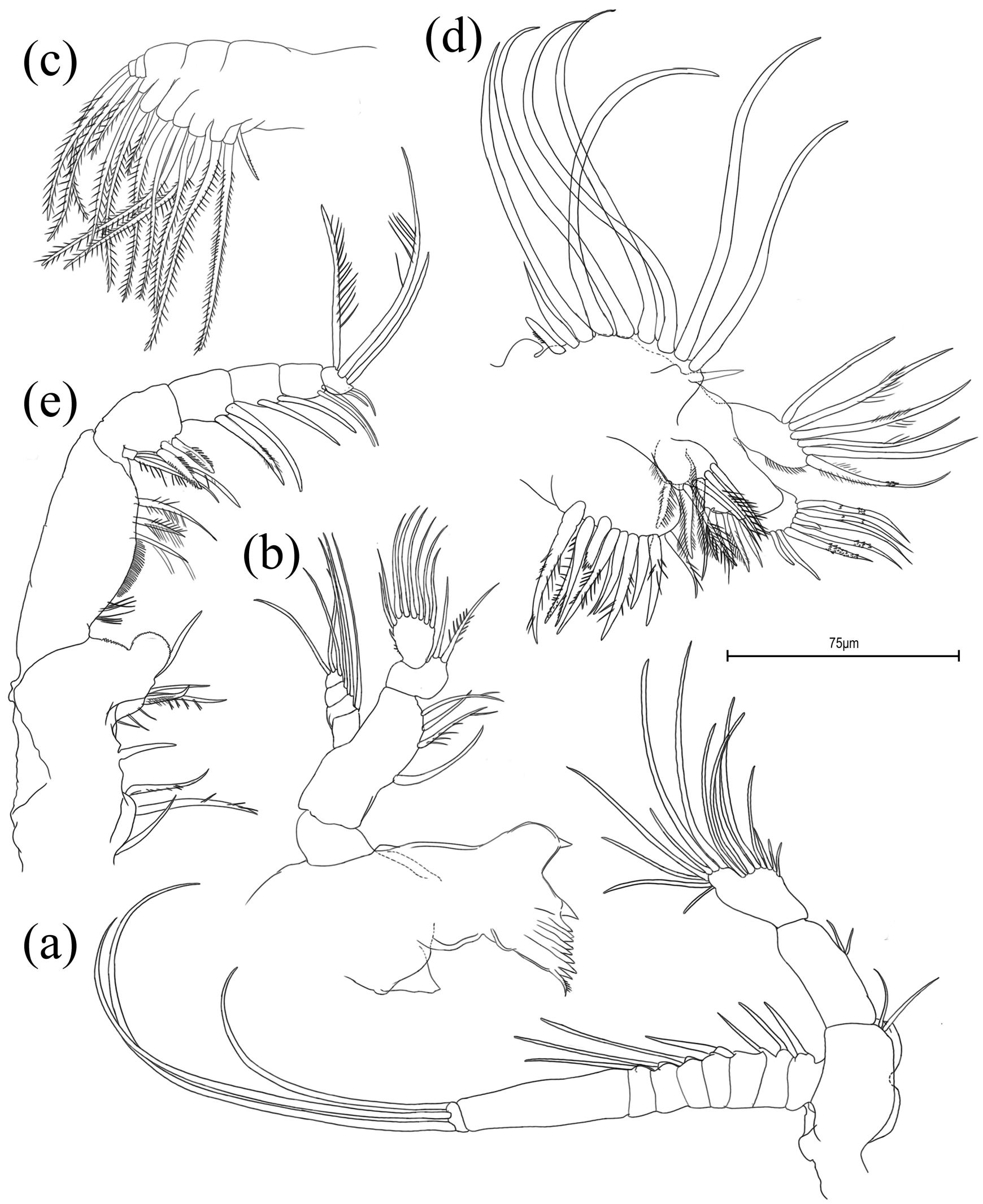

Figure 3. Phyllodiaptomus (Ctenodiaptomus) praedictus sulawensis. A, antenna; B, mandible; C, maxilla; D, maxillule; E, maxilliped. 


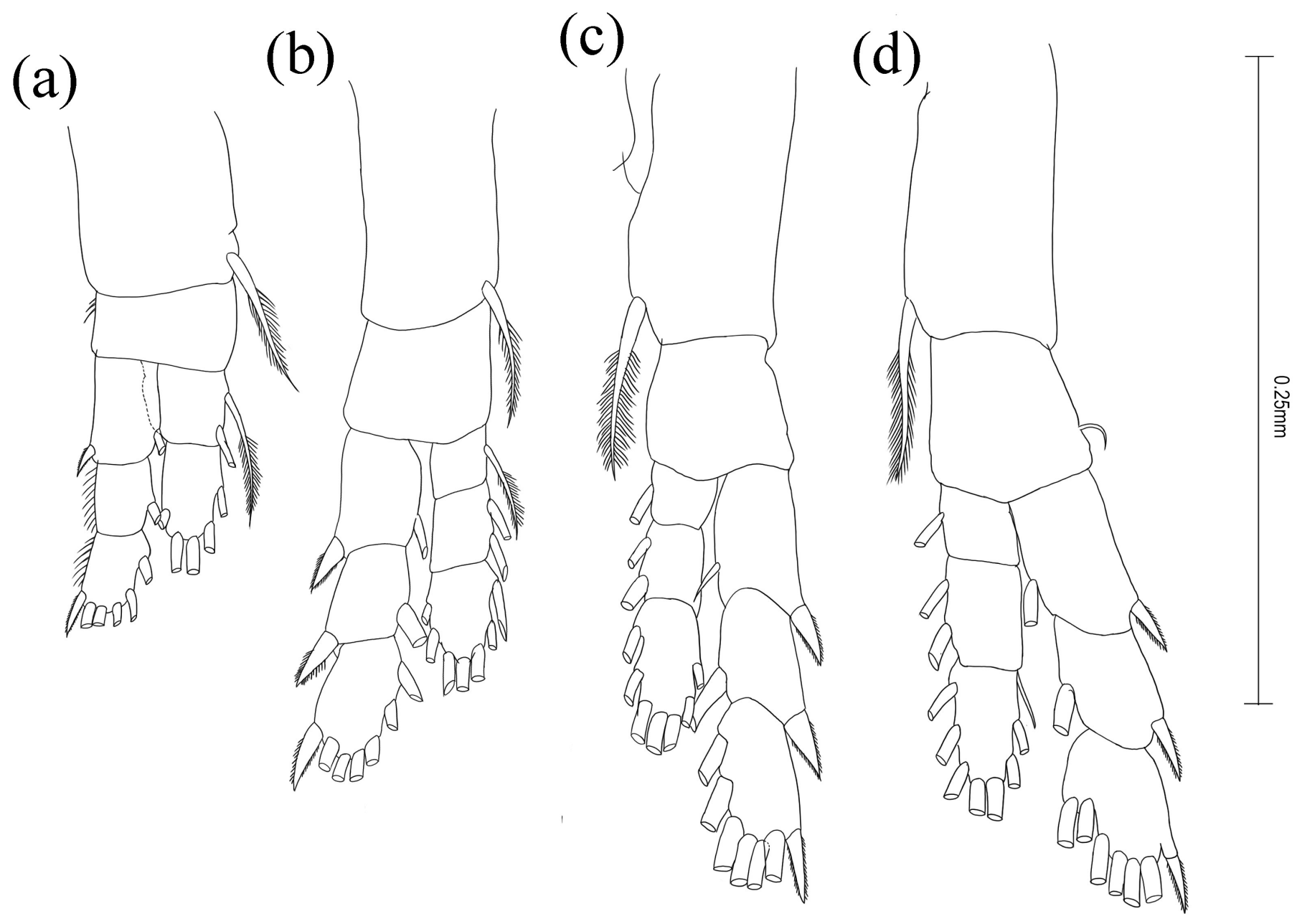

Figure 4. Female Phyllodiaptomus (Ctenodiaptomus) praedictus sulawensis. A, first pediger; B, second pediger; C, third pediger; $D$, fourth pediger.

exopod. Endopod 2-segmented with four setae on first, and seven on second segment.

First to fourth pedigers (P1-P4; Fig. 4) with normal complement of setae and spines of the subfamily Diaptominae. Similar for both male and female.

\section{Adult Male}

Habitus (Fig. 5) Mean total length exclusive of furcal setae $1.14 \mathrm{~mm} \pm 0.04 \mathrm{~mm}(\mathrm{n}=30)$. Rostral spines similar in female, but slightly smaller. Fourth and fifth pedigerous somite separated by a distinct septum. Lateral wings of fifth pedigerous somite small, triangular; spines on the left size smaller than the spines on the right side.

Right antennule (A1; Fig. 5-I) geniculate, 22-segmented, with spines on segments 8 and 10-16 (Figs. 5-J, K) longest spine found on segment $13,18^{\text {th }}$ to $20^{\text {th }}$ segments longest; segments 11 and 13 with aesthetascs shaped as spines with incised tip; relative lengths of spine as follows: $13>11>10$ $>15>8>12>14>16$; two long setae found on the antepenultimate segment, with a relatively large comb-like process, with 4-8 teeth, some specimens may vary in sizes (Figs. 5-L, M); armature summarized as: 2-4, 5-6, $21=2$; $8=$ $2+1$ spine; $9=2 ; 10-12=1+1$ spine; $13=1$ spine; $14-16=$ $1+1$ spine + ae; $17=$ ae; $20=2+$ ae; $22=4$. Armature of left $A 1$ similar in female, except for minor differences in length of setae.

Fifth leg (P5; Fig. 5-D) asymmetrical, left P5 smaller than right P5. Right P5 coxa shaped into a large triangular plate at the distal inner corner, presence of a pointed and posteriorly oriented distal region, armed with a strong conical spine, projecting from a lobular structure at the distal inner corner of posterior surface. Basis rectangular in shape, longer than wide, with small triangular ridge-like protrusion (Fig. 5-F) at the distal inner region of basis; large, bilobed hyaline lamella located at inner margin; proximal region with longitudinal chitinous ridge at the middle, distomedial with sensory 


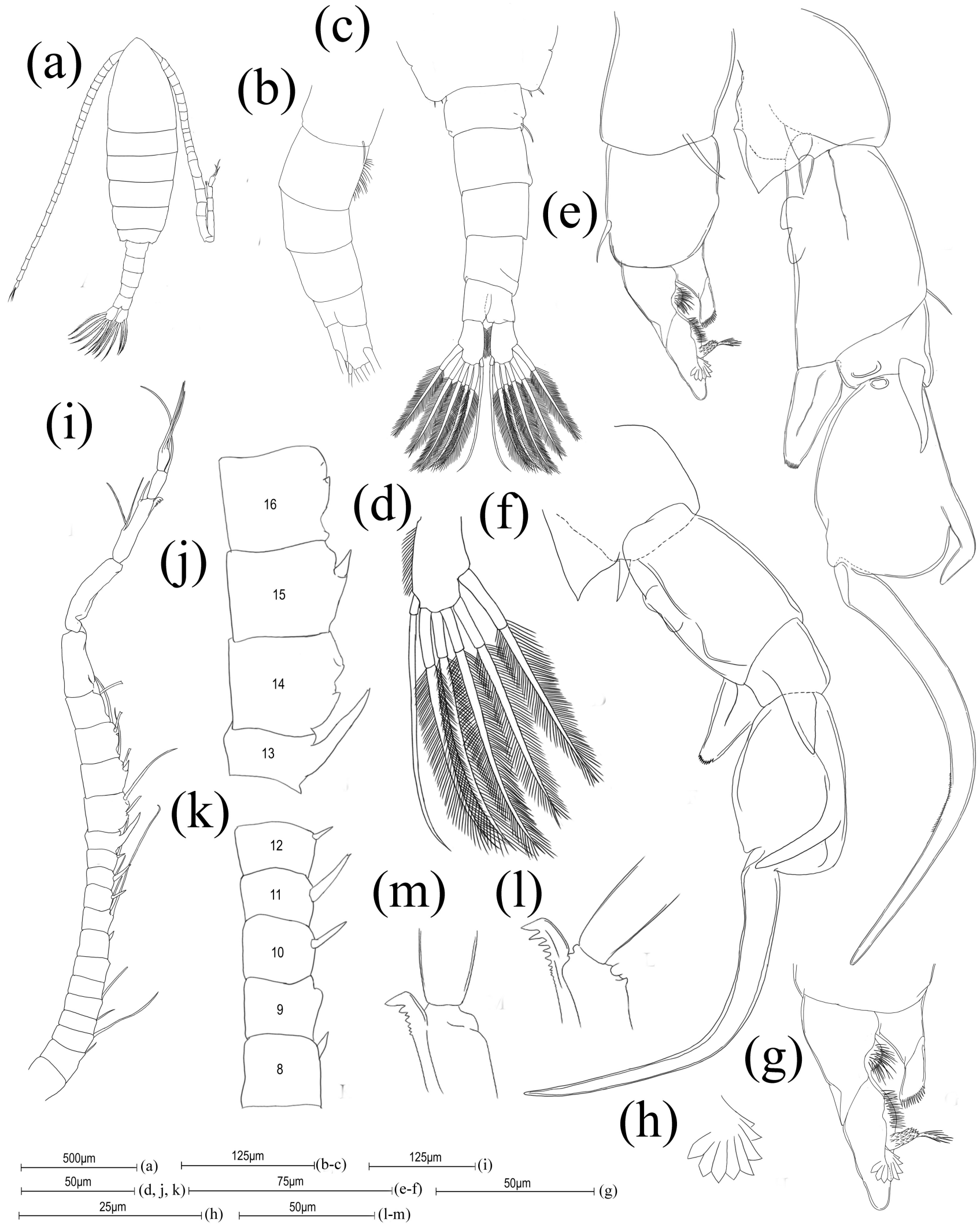

Figure 5. Male Phyllodiaptomus (Ctenodiaptomus) praedictus sulawensis. A, dorsal habitus; B, urosome in lateral view; C, urosome in dorsal view; $\mathrm{D}$, caudal rami in dorsal view; $\mathrm{E}, \mathrm{P} 5$; $\mathrm{F}$, right $\mathrm{P} 5$; $\mathrm{G}$, left $\mathrm{P} 5$; $\mathrm{H}$, terminal membranous hyaline fan of right P5; I, right antennule; J, segments 13-16; K, segments 8-12; L-M, antepenultimate comb. 
seta. Exopod two-segmented; first exopod segment about twice as wide as it is long, with sturdy slightly incurved spine at outer distal corner, spinous process may vary in shape; presence of crescent-shaped hyaline lamella near the inner distal region. Second exopod segment spoon-shaped, about twice as long as wide, posterior surface curved inwards, small lobed hyaline lamella at mid-proximal margin of the base, hyaline lobe absent at the outer distal corner of the posterior surface and lateral digitiform appendix protruding somewhat posterior to the mid-outer margin. Terminal claw immediately succeeding the second exopod segment, slender, sickleshaped with a blunt tip and armed with numerous spinules on the inner margin at the middle region. Endopod tapering from the proximal to distal region, inwardly curved tip with a row of fine apical spinules, posterior surface with a longitudinal chitinous ridge.

Left P5 (Fig. 5-G) reaching the length of the posterior border of basis of right P5, slightly incurved. Coxa somewhat rectangular, armed with long slender spine at distal inner corner. Basis lateral margins curved outwards, longer than wide, with small hyaline lamella at the inner margin, a sensory seta distally positioned at the outer corner. Exopod (Fig. 5-E) two-segmented, first exopod segment with lobe of hairs found on the distal inner margin. Second exopod segment shaped into a thumb-like process, tapering from the base to the apex, longitudinally-arranged rows of hairs located and covering the inner middle margin of the base, narrow hyaline lamella lining present near the apex, with a large inner seta, tapering distally, proximal half dilated and set with fine spinules; distal half narrower and covered with dense long setules and a large hyaline fan typically with 8 serrations located between the inner seta and digitiform thumb-like apex. Endopod twosegmented, small, flask-shaped, reaching near the base of the second exopod segment, apex obliquely pruned, with minute spine on each side and row of spinules at the apex.

Urosome (Fig. 5-B) of five somites. First segment with short, slim spine at right distal junction. Second segment ventral margin with longitudinally arranged rows of hair-like setae. Third segment without hair-like setae, wider than long. Fourth segment asymmetrical. Furca symmetrical, longer than wide, inner margins bearing fine setae, and with six pairs of furcal setae; lateral furcal seta slightly bigger than the others; presence of joints just before the start of setation found in all the setae except the inner lateral seta; dorsal seta without joints, lack setules along lateral sides as shown on (Fig. 5-C).

\section{Remarks on distribution}

$P$. (C.) praedictus sulawensis was found in the following localities within the Candaba Swamp: San Agustin (center of Candaba Swamp), a puddle of water beside the road in Donya Turo, an irrigation canal coming from Pantabangan
Dam, Nueva Ecija, and another in Barangay Pasig, a fishpond in Barangay Lanang and Barangay Loren de Guzman, a rice field in Barangay Patalaya and Barangay Panggatang, in Magumbali, and in Santa Rosario (Fig. 1). $P$. (C.) praedictus was initially recorded as an endemic species in Thailand (Dumont \& Reddy, 1994). However, Alekseev et al. (2013) was able to record its presence in Indonesia which resulted to the recognition of an endemic subspecies that is herein reported for the first time in the Philippines and outside its type locality. There were no samples collected from the northeastern parts of the municipality of Candaba because of the elevation, accessibility, and low water levels there.

\section{Discussion}

In 2013, calanoid samples collected from Candaba Swamp by R. Papa, H. Dumont \& E. Rizo (unpublished) were identified to belong to the genus Phyllodiaptomus but were not described in detail to ascertain its species-level identification. The availability of more recently collected samples have led us to confirm our initial generic identification and identify it up to subspecies level. In this paper however, we reported the second occurrence of $P$. (C.) praedictus in insular Southeast Asia and the first record of $P$. (C.) praedictus sulawensis outside its type locality possibly suggesting a wider geographic distribution. This indepth taxonomic work on the species was done in order to provide baseline information on the current specimens available in the country and in order to properly identify them up to subspecies level. These information have allowed us to compare the characters between $P$. (C.) praedictus, $P$. (C.) praedictus sulawensis, and the specimens collected in the Philippines (Tables $1 \&$ 2).

The occurrence of $P$. (C.) praedictus in Candaba Swamp, Luzon Island showed that the species is now more widely distributed than previously thought. This points to the successful dispersal of copepods through migratory birds from East Asia that pass through the eastern coast of Thailand before proceeding to Candaba Swamp over the course of their migration through the East Asian Australasian flyway (Bamford et al., 2008). In the process, the birds may carry with them resting copepod eggs that are dispersed either through excrement release or via dislodging from feathers and claws (Green \& Figuerola, 2005). More or less 20 avian species belonging to different groups such as but not limited to egrets, ducks, pelicans, herons, kingfishers, plovers, bitterns, shanks, sandpipers, hens, sparrows, owls, dovers, falcons, crows, bulbuls, geese, spoonbills, snipes, and wagtails (Jensen et al., 2015; Melendres, 2014; Ong et al., 2005; Redman, 1993) fly in and out of Candaba Swamp from different parts of Asia. It is hypothesized that $P$. (C.) 
Philippine Journal of Systematic Biology | Guinto, S.K.P. et.al.: New record of Phyllodiaptomus in the Philippines

Table 1. Comparison of characters between the species collected in this study with the identifying characters of Phyllodiaptomus (Ctenodiaptomus) praedictus based on Dumont \& Reddy (1993) and Dumont \& Reddy (1994).

MALE praedictus This study

Body size $(\mathrm{mm})$

$1.01-1.10$

$1.07-1.22$

Right lateral wing

- inner spine much smaller than apical spine

Urosome

- 2 alone with ventral hairs

Furca

- both rami symmetrical

- both rami without ventral armature

- lateral Fs undilated proximally

Right Antennule

- spine on segment 8 reduced

- antepenultimate segment with comb-like process

Right Fifth Leg: Coxa

- inner hyaline plate short, roughly triangular

Right Fifth Leg: Basis

- inner margin with 2 hyaline lobes

Right Fifth Leg: distal outer corner of first exopod segment

-with large spinous process

Right Fifth Leg: Second exopod segment

- oval or elongately oval

- lateral spine thick, digitiform and distal

-without hyaline lobe

Right Fifth Leg: terminal claw

- slender

Right Fifth Leg: shape of Endopod

- almost pyriform with dilated base

Left Fifth Leg: Second exopod segment

- with fan-like outgrowth between apical thumb and inner seta

Left Fifth Leg: shape of endopod

- roughly flask-shaped with dilated base 
Philippine Journal of Systematic Biology | Guinto, S.K.P. et.al.: New record of Phyllodiaptomus in the Philippines

Table 2. Comparision of characters between the species collected in this study and the characters differentiating P. (C.) praedictus from P. (C.) praedictus sulawensis based on Alekseev et al. (2013).

\begin{tabular}{cccc}
\hline MALE & P. (C.) praedictus & $\begin{array}{c}P \text {. (C.) praedictus } \\
\text { sulawensis }\end{array}$ & This Study \\
\hline $\begin{array}{c}\text { Right antennule } \\
\text {-comb on antepenultimate } \\
\text { segment }\end{array}$ & 4-7 large equal-sized teeth & 2-3 large and 4-5 tiny teeth & 2-3 large and 4-5 tiny teeth \\
-spine on segment 13 & $\begin{array}{c}\text { Sharply bent over spine on } \\
\text { segment } 14\end{array}$ & $\begin{array}{c}\text { Never bent over distal end } \\
\text { of the spine on segment } 14\end{array}$ & $\begin{array}{c}\text { Never bent over distal end } \\
\text { of the spine on segment } 14\end{array}$ \\
-segment 15 & $\begin{array}{c}\text { With relatively long spine } \\
\text { reaching the end of the } \\
\text { segment }\end{array}$ & With very short spine & With very short spine \\
\hline
\end{tabular}

praedictus sulawensis may have been naturally introduced in the area through avian migratory traffic. The presence of migratory species in the area brings with it potentially interesting new records of copepods, such as $P$. (C.) praedictus sulawensis, since birds are an established agent of dispersal for copepods (Green \& Figuerola, 2005). This means of dispersal is unlike the one observed for another non -indigenous zooplankton recently documented in the Philippines - the Neotropical Arctodiaptomus dorsalis, which is known to have been introduced from the Americas through ship drinking water reserves and the trade of tropical aquarium fishes which was then spread to various localities through the transfer of aquaculture fishes (Lopez et al., 2017).

Although there are anthropogenic activities occurring in the area, mainly small-scale aquaculture in privately-owned fish ponds using non-native fish, agriculture during the dry season, and fishing during the rainy season, such activities could not have been the primary vector for dispersal of the copepod species because the sources of these activities are restricted locally.

\section{CONCLUSIONS AND RECOMMENDATION}

This paper presents $P$. (C.) praedictus sulawensis from Candaba Swamp, Pampanga as a new record in the country, the first record outside its type locality in Indonesia, and the second record in insular Southeast Asia. It is suggested that $P$. (C.) praedictus sulawensis was naturally introduced into the country via avian migration. Also, we have provided the most basic information for the identification of the Philippine members of this particular species which will be useful in the future for constructing an updated taxonomic key for Philippine inland water calanoid copepods. Our results showed how Candaba Swamp in Pampanga may harbor high species richness for "non-charismatic" fauna such as copepods which may have been dispersed through avian migration which occurs annually in the region.

\section{ACKNOWLEDGEMENTS}

The authors would like to acknowledge the reviewers for their valuable input leading to the great improvement of this paper. Their comments and suggestions have enlightened us with regards the true identity of the Philippine Phyllodiaptomus thus leading to its publication. Also, we would like thank the Candaba Municipality Tourism Office for the assistance provided during the field work. We would like to thank the Department of Science and Technology-Science Education Institute for the scholarship grants to Shea Guinto and Eric Zeus Rizo during the course of the study. We would also like to acknowledge the support from the grant for leading talent scientists of Guangdong Province to Henri Dumont and the National Basic Research Program of China (No. 2012CB956100) and the National Science FoundationChina (No. 31670460) for Bo-Ping Han.

\section{LITERATURE CITED}

Alekseev, V.R., Haffner, D.G., Vaillant, J.J., \& Yusoff, F.M. (2013). Cyclopoid and calanoid copepod biodiversity in Indonesia. Journal of Limnology, 72: 245-274.

Bamford, M., Watkins, D., Bancroft, W., Tischler, G., \& Wahl, J. (2008). Migratory shorebirds of the East Asian Australasian flyway: Population estimates and Internationally Important Sites. Wetlands International Oceania. Canberra, Australia.

Dumont, H. J., \& Reddy, Y. R. (1993). A reappraisal of the genus Phyllodiaptomus Kiefer, 1936, with the description of $P$. wellekensae n.sp. from India, and a redescription of $P$. tunguidus Shen \& Tai, 1964 from China (Copepoda, Calanoida). Hydrobiologia, 263: 65-93. 
Dumont, H. J., \& Reddy, Y. R. (1994). Phyllodiaptomus praedictus n. sp. (Copepoda, Calanoida) from Thailand, Hydrobiologia, 273: 101-110.

Dumont, H. J., Reddy, Y. R., \& Sanoamuang, L. (1996). Description of Phyllodiaptomus christineae n.sp. from Thailand and distinction of two subgenera within Phyllodiaptomus Kiefer, 1936 (Copepoda, Calanoida). Hydrobiologia, 323: 139-148.

Dussart, B. H., \& Defaye, D. (2001). Introduction to the Copepoda. Backhuys Publishers, Leiden, Netherlands.

Green, A. J., \& Figuerola, J. (2005). Recent advances in the study of long- distance dispersal of aquatic invertebrates via birds. Diversity and Distributions, 11: 149-156.

Jensen, A. E., Fisher, T. H., \& Hutchinson, R. O. (2015). Notable new bird records from the Philippines. Forktail, 31: 24-36.

Lai, H. C., \& Fernando, C. H. (1980). Zoogeographical distribution of Southeast Asian freshwater Calanoida. Hydrobiologia, 74: 53-66.

Lai, H. C., Mamaril Sr., A., \& Fernando, C. H. (1979). The freshwater Calanoida (Copepods) of the Philippines. Crustaceana, 37(3): 225-240.

Lopez, M. L. D., Pascual, J. A. F., Dela Paz, E. S. P., Rizo, E. Z. C., Tordesillas, D. T., Guinto, S. K. P., ... Papa, R. D. S. (2017). Annotated checklist and insular distribution of freshwater microcrustaceans (Copepoda: Calanoida \& Cyclopoida; Cladocera: Anomopoda \& Ctenopoda) in the Philippines. Raffles Bulletin of Zoology, 65: 623-654.

Melendres, R. G. (2014). The utilization of Candaba Swamp from prehistoric to present time: Evidences from archaeology, history and ethnography. Bhatter College Journal of Multidisciplinary Studies, 4: 81-93.

Ong, P. S., Luna, M. P. G., Rosales, R. M. P., Bantayan, N. C., Custodio, C. C., Balete, D. S., ... Mendoza, M. M. (2005). UNEP/GEF Project: Reversing environmental degradation trends in the South China Sea and Gulf of Thailand - Philippines National Report on Wetlands. Quezon City, Philippines.

Redman, N. (1993). Two new species of birds for the Philippines and other notable records. Forktail, 8: 119124.

Round, P. D., \& Fisher, T. H. (2009). Records of blackbrowed reed warbler Acrocephalus bistrigiceps from Luzon, Philippines. Forktail, 25: 159-160.

Sanoamuang, L., \& Yindee, W. (2001). A new species of Phyllodiaptomus (Copepoda, Diaptomidae) from northeast Thailand. Crustaceana, 74(5): 435-448.

Van Weerd, M., \& Van Der Ploeg, J. (2004). Surveys of wetlands and waterbirds in Cagayan Valley, Luzon, Philippines. Forktail, 20: 33-39. 